\title{
Optimization of Ultrasonic Extraction Method of Natural Dyes from Xylocarpus Moluccensis
}

\author{
Norul Azilah Abdul Rahman, Siti Marsinah Tumin, and Ruziyati Tajuddin
}

\begin{abstract}
Problem statement: Traditionally the extraction of natural dyes from plant materials was done by soaking method or boiling method which requires longer extraction time, higher temperature and higher consumption of water. Extractions of colorant using boiling method normally produce a small amount of yield. Low yield of natural dyes is one of the factors that limit the use of natural dyes in comparison with synthetic dyes. Hence, there is a growing demand for developing suitable extraction technique for more efficient and effective extraction of natural textile dyes. Approach: This study demonstrated ultrasonic cleaner as a technique to extract colorant from a selected plant, i.e Xylocarpus moluccensis species which can be found abundantly in peninsular Malaysia. Colorant from combination of heartwood and bark of Xylocarpus moluccensis was extracted at different ultrasonic volume, time and temperature. The color strength of the dye was analyzed by using Lab Scan XE UV-visible spectrophotometer. Result: Results show the highest percentage of total yield dye extract using ultrasonic cleaner was produced at optimum condition (extraction time: 80 minutes, extraction temperature: $49^{\circ} \mathrm{C}$ and sonic volume: medium) with $80 \mathrm{ml}$ of $0.1 \mathrm{M}$ sodium hydroxide as the solvent. The yield produced was higher than that of boiling method and thus gave higher intensity of red crude extract. Conclusion: The utilization of ultrasonic cleaner was found to have significant improvement in the extraction of natural dyes compared to traditional boiling method.
\end{abstract}

Index Terms-UV-visible spectrophotometer, ultrasonic cleaner, natural dye, colorant, anthraquinone

\section{INTRODUCTION}

Xylocarpus moluccensis, commonly known as Nyireh batu in Malay belongs to family of Meliaceae, which can be found abundantly in littoral forest of the Malaysia Peninsula, Bengal, Burma, the Andaman's, Australia, Fiji and Africa [1]. The features of the Xylocarpus moluccensis are 5 to $20 \mathrm{~m}$ tall, compound leaf comprising of 2 to 3 pair of leaflets that are oblong with more pointed tip, thin and leathery (green color), the flowers are tiny white to yellowy, the fruits are green in color and round shape and bark are longitudinal fissures and hath dark grey color.

According to Giesen et al., [2], Xylocarpus moluccensis is used widely in timber production for construction of houses and boats. Aborigine people (Mah Meri community) of Pulau Carey, Malaysia are famous for its unique wooden statues and masks carved from Xylocarpus heartwood. The

Manuscript received September 19, 2012, revised November 30, 2012.

This work was supported by research funding from Universiti Teknologi MARA (UiTM).

Ruziyati Tajuddin is with Department of Chemistry, Faculty of Applied Sciences, Universiti Teknologi MARA (UiTM) (e-mail: ruziy039@salam.uitm.edu.my). waste from this handcraft production is useful as a source of natural dyes for this study. Previously, Abd Razak et al., [3] reported Xylocarpus moluccensis heartwood as one of the potential natural dyes sources. They discovered that the colorant extracted corresponds to anthraquinone compound.

Recently, there is a growing demand for developing suitable efficient extraction technique for natural dyes from plants materials. Ultrasonic approach has been widely used mainly in food industry [4]-[6] and also in textile industry [7]-[9].

Cuoco et al., [8] used ultrasonic-assisted extraction based on central composite design to extract dyes originally biosynthesized by the plant. Recently, Sivakumar et al., [7] found that the application of ultrasonic probe can increase the extraction of dyes from different parts of various plants resources. The reason for the improvement could be due to better leaching of natural dyes materials from plant cell wall membranes and mass transfer to solvent assisted by acoustic cavitations provided by ultrasonic. Kamel et al., [9] used ultrasonic bench top cleaner bath for dyeing cloth fabric using colorant from Cochineal dye. They reported that the ultrasound approach improved dyeability as well as enhancement in the fastness properties of the dyed fabric.

In this study ultrasonic cleaner approach was used in both extraction and dyeing process. Ultrasonic cleaner has a more uniform and wider waves compared to ultrasonic probe and ultrasonic- assisted extraction based on central composite design. As a result, various pattern can be examined at the same time hence reduce time, cost and energy. Whereas in the other two latter methods, waves occur only at a limited area. Therefore, more time and exertion are required to examine each pattern which consumes more energy and cost.

\section{MATERIALS AND METHOD}

\section{A. Raw Materials.}

The waste of heartwood and bark of Xylocarpus moluccensis was collected from the craft small industry located in the village at Pulau Carey, Klang Selangor, Malaysia. The sample was then ground and stored at room temperature before use.

\section{B. Chemical}

\section{Sodium hydroxide}

\section{Ultrasonic Extraction Method}

Approximately $7 \mathrm{~g}$ of bark and $1 \mathrm{~g}$ of heartwood was weighed and placed in the bottle. $80 \mathrm{~mL}$ of $0.1 \mathrm{M}$ sodium hydroxide was added. The bottle was then placed into the ultrasonic cleaning for extraction process. Parameter optimized were ultrasonic volume (low, medium and high), 
extraction time $(20,40,60,80$ and 100 minutes $)$ and temperature was read after the extraction.

All extracts were filtered by using vacuum pump and dried using freeze dried. After sample was dried, the weight was measured and recorded.

$$
\% \text { Yield of total extract }=\frac{\text { Total extract obtained }(\mathrm{g})}{\text { Amount of sample used }(\mathrm{g})} \times 100
$$

\section{Boiling Method}

Approximately $7 \mathrm{~g}$ of bark and $1 \mathrm{~g}$ of heartwood was weighted and placed in the bottle. $80 \mathrm{~mL}$ of $0.1 \mathrm{M}$ sodium hydroxide was added. The sample was boiled using for 80 min at atmospheric pressure. All extracts were filtered by using vacuum pump and dried using freeze dried. After sample was dried, the weight was measured and recorded.

\section{E. Chemical Analysis}

The reflectance/ transmittance and color strength of the extract sample was measured using Lab Scan XE UVvisible spectrophotometer at the wavelength range of 400$700 \mathrm{~nm}$.

\section{F. Color Measurement}

Color of extract was measured using Lab Scan XE UVvisible spectrophotometer based on CIE system (International Commission on Illumination). The reference illuminant was D65 (standard daylight), expressed as $L^{*}, a^{*}$ and $b^{*}$ which representing lightness $\left(L^{*}\right)$, redness $\left(+a^{*}\right)$, greenness $\left(-a^{*}\right)$, yellowness $\left(+b^{*}\right)$, and blueness $\left(-b^{*}\right)$. From the $L^{*}, a^{*}$ and $b^{*}$ coordinates, chroma $\left(C^{*}\right)$ and hue angle $\left(h^{\circ}\right)$ values were calculated by using the following equation:

$$
\text { G. } \quad C^{*}=\sqrt{ }\left(a^{* 2}+b^{* 2}\right) \text { and } h^{\mathrm{o}}=\tan ^{-1}\left(b^{*} / a^{*}\right)
$$

Chroma measures the intensity or saturation of the colorant while hue angle $\left(h^{\circ}\right)$ is expressed on $360^{\circ}$ grid to show the tonality of the color. Hue angle $\left(h^{\circ}\right)$ represents red at $0^{\circ}$ (or $360^{\circ}$ ), blue at $270^{\circ}$ (or $-90^{\circ}$ ), yellow at $90^{\circ}$ and green color at $180^{\circ}$ (or $-80^{\circ}$ ).

\section{RESULTS}

Extraction of natural dyes from combination of bark and heartwood of Xylocarpus moluccensis was done using $0.1 \mathrm{M}$ sodium hydroxide as a solvent. A preliminary study consisting of various experiments were carried out in order to determine the role of extraction time and ultrasonic volume involved in the ultrasonic-assistance extraction of Xylocarpus moluccensis. The percentage yield of dye extract of Xylocarpus moluccensis obtained is tabulated in Table I and the plot is shown in Fig. 1.

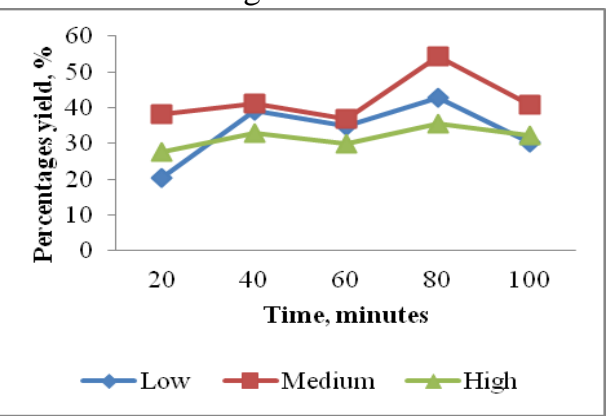

Fig. 1. Effect of extraction time and sonic volume on \% yield
As shown in Fig. 1, the percentage yield of dye extract of Xylocarpus moluccensis increased with the increasing of the extraction time and reached maximum at 80 minutes. A further increase in time resulted in a declined plot.

Ultrasonic volume is an important parameter for the ultrasonic-assistance extraction as the effectiveness of the dye extract depends on it. Results in Table I show that the highest percentage yield of dye extract was produced at medium sonic volume.

The extraction using ultrasonic cleaner at optimum condition was then compared to the classical boiling method. The results in Fig. 2 show that the extraction yield obtained by ultrasonic extraction method increased by $54.22 \%$ as compared to boiling method.

The analytical measurement of aqueous plant extract is important in order to control the quality and standardization of the natural colorant prior to further application such as textile dyeing. In this study, the measurement of $L^{*}, a^{*}, b^{*}$ as well as $h^{\circ}$ and chroma $C^{*}$ values was used to evaluate the color of crude dyes from combination of bark and heartwood of Xylocarpus mollucensis obtained by both ultrasonic and boiling methods.

\begin{tabular}{lrcc} 
TABLE I: PERCENTAGE YIELD OF TOTAL EXTRACT USING UlTRASONIC \\
\hline Time, minutes & \multicolumn{3}{c}{ Percentage yield of total extract, \% } \\
\cline { 2 - 4 } & $\begin{array}{l}\text { Low } \\
\text { frequency }\end{array}$ & $\begin{array}{l}\text { Medium } \\
\text { frequency }\end{array}$ & $\begin{array}{l}\text { High } \\
\text { frequency }\end{array}$ \\
\hline 20 minutes & 20.27 & 38.1 & 27.72 \\
40 minutes & 39.31 & 41.22 & 32.86 \\
60 minutes & 34.81 & 36.83 & 30.04 \\
80 minutes & 42.96 & 54.22 & 35.69 \\
100 minutes & 30.38 & 40.71 & 32.38 \\
\end{tabular}

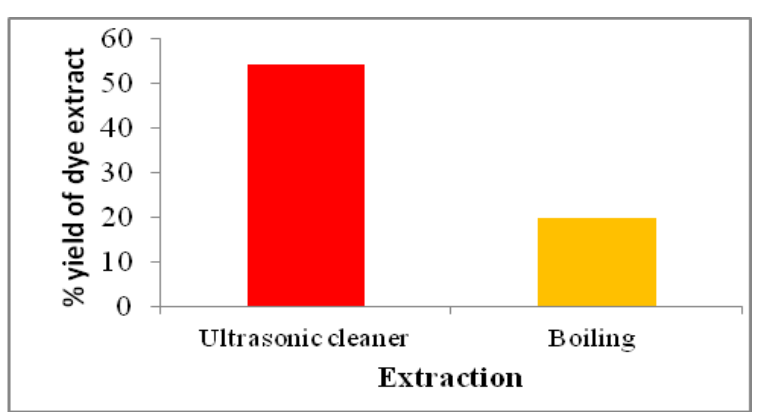

Fig. 2. Comparison of $\%$ yield of dye extract obtained using ultrasonic and boiling methods in 80 minutes time.

Table II shows the values of $L^{*}, a^{*}, b^{*}$ obtained from measurement using Lab Scan XE UV-spectrophotometer based on CIE system. Hue angle, $\mathrm{h}^{\mathrm{o}}$ and chroma, $C^{*}$ values were calculated using the formula mentioned earlier.

The value of $a^{*}$ which indicates the redness effect for crude dye extract was significantly higher by using ultrasonic extraction compared to boiling method. The values of $\mathrm{a}^{*}$ and $b^{*}$ contribute to $h^{\circ}$ value of $45^{\circ}$ which show that the color of crude dyes extract obtained by ultrasonic extraction method was red-orange. While, the color of crude dye extract obtained by boiling method was more to yellowish orange as represent by hue angle of $55.4^{\circ}$ 
TABLE II: COLOR MEASUREMENT OF CRUDE Dye EXTRACTS OBTAINED BY USING ULTRASONIC AND BOILING METHODS.

\begin{tabular}{lccccc} 
Method & $L^{*}$ & $a^{*}$ & $b^{*}$ & $C^{*}$ & $h^{\text {o }}$ \\
\hline Ultrasonic & 0.18 & 0.31 & 0.31 & 0.44 & 45.0 \\
Boiling & 0.17 & 0.2 & 0.29 & 0.35 & 55.4 \\
\hline \\
angle, $C^{*}=$ chroma
\end{tabular}

The intensity or saturation of colorant is represented by chroma, $C^{*}$ value. The $C^{*}$ value of 0.44 indicates that dye extract obtained by ultrasonic cleaner extraction was more saturated compared to extract obtained by boiling method $(0.35)$

\section{CONCLUSION}

The use of ultrasonic extraction method was found to have significant improvement in the percentage yield, color intensity and redness color of crude dye extract compared to traditional boiling method. In this study, the operating condition for the ultrasonic extraction of natural dye from Xylocarpus moluccensis was optimized at 80 minutes with medium sonic volume and temperature of $49^{\circ} \mathrm{C}$.

\section{ACKNOWLEDGEMENT}

We wish to express our gratitude to the Faculty of Applied Sciences, Universiti Teknologi MARA Shah Alam for the support.

\section{REFERENCES}

[1] S. J. Uddin, J. A. Shilpi, S. M. S Alam, M. Alamgir, M. T. Rahman, and S. D. Sarker, "Antidiarrhoel activity of the methanol extract of the barks of Xylocarpus moluccensis in castor oil- and magnesium sulphate-induced diarrhea models in mice," Journal of Empharmacology, vol. 101, pp. 139-143, 2005.

[2] W. Giesen, S. Wuffraat, M. Zieren and L. Scholten, Mangrove Guidebook for Southeast Asia. Food and Agriculture Organization of the United Nations Regional Office for Asia and the Pacific Bangkok, RAP publication, 2006.

[3] N. A. Razak, S. M. Tumin, and R. Tajuddin, "Effect of temperature on the color of natural dyed extract using pressurized hot water extraction method," American Journal of Applied Sciences, vol. 8, no. 1, pp. 45-49, 2011.

[4] S. R. Pai, M. S. Nimbalkar, N. V. Pawar, and G. B. Dixit, "Optimization of extraction technique and quantification of Betulinic acid (BA) by RP-HPLC method from Ancistrocladus heyneanus Wall," Ex Grah. Industrial Crops and Products, vol. 34, pp. 14581464, 2011.

[5] G. Zhang, L. He, and M. Hu, "Optimized ultrasonic-assisted extraction of flavonoids from Prunella vulgaris L. and evalution of antioxidant activities in vitro," Innovative Food Science and Emerging Technologies, vol. 12, pp. 18-25, 2011.

[6] M. H. Lee and C. C. Lin, "Comparison of techniques for extraction of isoflavones from the root of Radix Puerariae: Ultrasonic and pressurized solvent extractions," Food Chemistry, vol. 105, pp. 223228, 2011.

[7] V. Sivakumar, J. Vijaeeswarri, and J. Lakshmi Anna, "Effective natural dye extraction from different plant materials using ultrasound," Industrial Crops and Products, vol. 33, pp. 116-122, 2011.

[8] G. Cuoco, C. Mathe, P. Archier, F. Chemat, and C. Vieillescazes, "A multivariate study of performance of an ultrasound-assisted madder dyes extraction and characterization by liquid chromatographyphotodiode array detection." Ultrasonic Sonochemistry, vol. 16, pp. 75-82, 2009.

[9] M. M. Kamel, M. M. El Zawahry, N. S. E. Ahmed, and F. Abdelghaffar, "Ultrasonic dyeing of cationized cotton fabric with natural dye," Part 2: cationization of cotton using Quat 188. Industrial Crops and Products, vol. 34, pp. 1410-1417, 2011. 